by King Umberto I of Italy in 1896. Later, the institute was described by Harry Platt as the "Mecca of orthopaedics." 11

The library boasts one of the finest collections of scientific journals and books on orthopaedics, and its shelves are filled with works that have made the history of this discipline. It has often been remembered kindly in the writings of foreign doctors. ${ }^{12-14}$ Besides providing daily help to the medical profession, the library is visited every year by doctors from all over the world when they attend international conferences at the institute, taking back home a memory of this very special place, whose motto is "Trattenete le idee ma restituite i libri"-"Take the ideas away with you, but please leave the books on the shelves."

We thank Giuseppina Sivieri, Laura Curia, Liliana Draghetti, Anna Di Nardo for their valuable historical research and Keith Smith for translating the article.

Contributors: AV had the idea and did bibliographic research, PT wrote the article, CM edited it, and PP revised it. PP is guarantor. Funding: No additional funding.

Competing interests: None declared.

Tondi B. I fasti olivetani. Venezia: Brigonci, 1684:162-3

2 Stagni S. Domenico Maria Canuti ed Enrico Haffner. The frescoes of the library. In: Cioni A, Bertoli Barsotti AM, eds. The Rizzoli Orthopaedic Insti- tute in San Michele in Bosco. Bologna: Istituti Ortopedici Rizzoli, 1996.213-9.

3 Pietro Rosini da Lendinara. Archivio storico Abbazia di Monte Oliveto Maggiore (SI).

4 Campanacci M. Francesco Rizzoli's dream (1809-1880). Chir Organi Mov 1998;83:317-21

5 Furfaro D. Alessandro Codivilla, chirurgo ortopedico. Chir Organi Mov 1964;53:75-8.

6 Vigano' A, Tomba P, Brillante C. Foreign visitors at the Rizzoli Orthopaedic Institute from 1912 to 1940. Chir Organi Mov 1995;80:101-4.

Benini A, Bonar SK. Andreas Vesalius 1514-1564. Spine 1996;21: 1388-93.

8 Vigano' A, Tomba P, Merlini L. A manuscript worth a villa. Acta Orthop Scand 1999;70:531-5.

9 Garrison FH. An introduction to the history of medicine. 2nd ed. Philadelphia: Saunders, 1917:144-145.

10 Tower P. Notes on the life and work of George Bartisch. AMA Arch Oph thalmol 1956;56:57-70.

11 Platt H. Orthopaedics in continental Europe 1900-1950.J Bone Joint Surg Br 1950;32:570-83.

12 Moutier G. L'Institut Rizzoli. Paris Med 1923;18:51-4

3 Pallardy G. Roentgen et la decouverte des rayons X. J Radiol 1995;76:1033-6.

4 Steindler A. A visit to some of orthopaedic clinics of Europe.J Bone Join Surg 1923;21:127-34

15 Bertram C, Nielander KH, Konig DP. Pioniere der Extremitatenverlangerung.Chirurg 1999;70:1374-8.

Kaplan EB. Development of tendon surgery in the past 50 years. Clin Kaplan EB. Developm

Orthop 1966;44:65-72.
17 Peltier LF. The role of Alessandro Codivilla in the development of skeletal traction.J Bone Joint Surg Am 1969;51:1433.

18 Vittorio Putti 1880-1940 [obituary]. N Engl Med J 1940;233:955-6.

9 Vittorio Putti, March 1, 1880-November 1, 1940. J Bone Joint Surg 1941;23:187-9.

20 Merlini L, Tomba P, Vigano' A. Berengario da Carpi, a pioneer in anatomy, rediscovery by Vittorio Putti. Neuromuscul Disord 2003;13:421-5.

doi 10.1136/bmj.39006.748634.47

\title{
Daisy the Doctor, Dr Dose, Dr Grizzly, Dr Amelia Bedelia, and colleagues
}

Monica Lalanda, Juan Antonio Alonso

Leeds Teaching Hospitals, Leeds LS1 3EX

Monica Lalanda staff grade in emergency medicine

Stepping Hill Hospital, Stockport SK2 7JE

Juan Antonio

Alonso

specialist registrar in

orthopaedic and

trauma surgery

Correspondence to: M Lalanda

lalanda@

doctors.org.uk

BMJ 2006;333:1330-2
The way children perceive the world is shaped by different factors. They can be strongly influenced from an early age. Many carers and teachers read books to children, and these might be their first encounter with a new subject. This can create certain expectations before children can have their own experiences.

Books for small children about "going to the doctor" are popular, and many adults will use them to help their youngsters cope with any related anxiety. They are common in children's wards and waiting areas for clinics and surgeries. By the time many children see a doctor they may have already looked at a book about doctors.

To our knowledge, there are no previous studies on books for children about doctors and hospitals and whether they present an accurate view. We looked at a series of books to investigate the image of doctors, their attitudes, and their jobs.

\section{Methods}

We selected 14 books written in English. The selection process was based on common factors for choosing children's books: colourful and appealing look (figures); reasonable price $(<£ 8(€ 12 ; \$ 15))$; and easily available.

Over a period of three months we browsed shelves in book shops and the internet using the search words "doctors" and "hospital." Half of the books had English publishers, and the others were either Canadian or American. Eleven books were first published from 2000 onwards and three were older (1981-95). We read the stories and studied their 366 illustrations, focusing on the 154 images of the 21 doctors in the books. We looked at different factors to assess how well they reflected reality.

\section{Results}

\section{The doctors' looks}

There are three common features to the doctors appearance: a white coat, a stethoscope, and a permanent smile. Only two doctors do not wear a white coat. One third of coats have pens sticking out of the pocket, and one is usually red. All doctors appear with a stethoscope, and most carry it all the time. Doctors are smiling in 126 out of the 154 pictures, even when they are performing examinations or talking. We attempted to examine each other's ears while smiling for a prolonged period of time and found it rather uncomfortable.

Twelve doctors are female, including two bears (Dr Bear and Dr Grizzly), and nine are male, including Dr Potts the dog. Of the humans, all but three are white.

None of the female doctors has hair long enough to touch their shoulders, and only two of the female doctors are blonde. We consider it inappropriate to 
comment on this fact. Clothes are very conservative. Only one male doctor does not wear a tie, and most female doctors wear flat shoes and skirts just below the knee. One third wear glasses, a high proportion compared with just two out of the 58 patients pictured. Most doctors look young, and only three might be middle aged. One general practitioner wears an indirect mirror on her forehead throughout the whole story but never uses it.

\section{The doctors' role}

Most doctors in these books are general practitioners, the others being an occupational health doctor, two emergency medicine physicians, one anaesthetist, and two surgeons. In one story the doctor is initially a general practitioner but then acts as a radiologist and subsequently a surgeon. We assume this is a "hospital at night scheme."

All the doctors seemed busy. Their hands are never at rest or they just hold an object such as a clipboard. One of the doctors complains that she saw 15 patients in 2 hours 20 minutes. We feel that a clinic of that size should be manageable provided that all cases are simple. They spend a long time talking to the patients and playing with the small children. They often allow the children to play with the instruments.

The doctors perform jobs that are traditionally done by other healthcare workers. They carry out seven paediatric check ups, involving weighing and measuring the children. They give the injections in five out of six immunisations. We assume that the nurses were probably on their break.

The doctors are generally appreciated by their patients. One gets a thank you card and another a present of ice cream. The patients all seem pleased about the service, and there are several mentions about the doctor being "friendly" and "nice." Most patients leave with a smile.

\section{Books included in this study}

Kottke J. A day with a doctor. Danbury, CT: Children's Press, 2000.

Karr K. At the doctor's. London: Collins, 1995.

Beylon C. At the hospital. Mineola, NY: Dover Publications, 2003.

Joyce M. Busy hospital. London: Ladybird, 2005. Parish H. Calling Doctor Amelia Bedelia. New York: HarperCollins, 2004.

Brooks F. Daisy the doctor. London: Usborne, 2004 Ross M. Doctor Daisy. London: Ladybird, 2002. Bourgeois P. Franklin goes to the hospital. New York: Scholastic, 2000.

Civardi A. Going to the doctor. London: Usborne First Experience, 2000.

Marx DF. Hello, doctor. Markham, ON: Children's Press, 2001.

Ahlberg A. Miss Dose the doctors'daughter. London: Puffin Books, 1988.

Cole J. My friend the doctor. New York: HarperCollins, 2005.

Berenstain S, Berenstain J. The Berenstain bears go to the doctors. New House, Random House/First Time Books, 1981.

Adamson J, Adamson G. Topsy and Tim go to the doctor. London: Ladybird, 2003.

\section{The doctors' tools}

Stethoscope-This is a permanent feature, and it appears in 125 of the total images. It is surprising to find that two thirds of the doctors carry it with the rigid arms around the neck. We assessed how plausible this might be. The earpieces pressed into the back of the head, the pressure over both carotids made us feel dizzy, and the distal end kept hitting the genitals. There is a great variety in the looks of the stethoscope. Some of

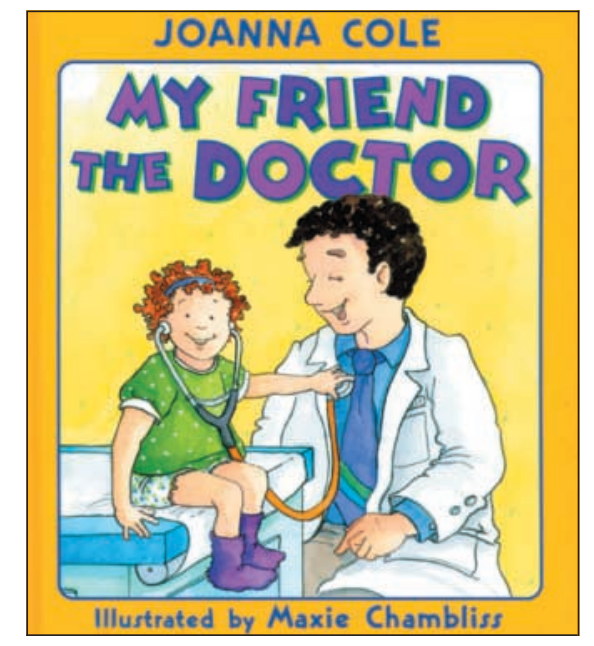
them are quite unusual.

Stethoscopes are used on 16 patients but applied only once on each of them. The places are variable: the axilla (three), shoulder (three), or the epigastrium (two). Auriscope-This is popular too. It is used 10 times for both ears and eyes. On six occasions the auriscope is used as a torch to look at the throat and on two occasions the earpiece is still attached to it. This would result in an illuminated area of $4 \mathrm{~mm}^{2}$. When the auriscope is used it barely touches the ear, and in only one illustration does the doctor pull the ear back.

Tongue depressor-Doctors examining the patients' throats use a tongue depressor and a light but the doctors' eyes always appear much higher than the children's mouths, making a successful examination unlikely.

Thermometer-This is seen nine times. All are mercury and glass. We are concerned about health and safety issues.

$X$ rays - We see a few examples. Interestingly one shows a foot next to a banana and another proves that "the child was brave inside." We are unaware of these advanced techniques.

\section{The doctors' office}

We see a total of 12 waiting rooms; only five look child friendly. The rest are crowded and dull. Patients waiting look upset or worried. At the general practitioner's, the staff is reduced to four nurses and three receptionists. Their attitude is always helpful. Unlike reality, the nurses' role seems to be limited to following the doctors' instructions. The desks display different items; the most common are telephones and tins with pens or tongue depressors. There are two family pictures.

Only two doctors have computers. These surgeries are in obvious need of some modernisation. Half of the offices have a framed picture that looks like a medical certificate.

\section{The doctors' skills}

The doctors' managerial skills seem good. There is no indication of waiting times. Seven of the stories start at home, and all patients seem to get an appointment immediately. The general practitioners deal with various minor complaints such as colds and coughs, minor trauma, skin problems, one fractured shell of a tortoise, and check ups.

The doctors do not hesitate in their diagnosis. In terms of treatment, six patients with colds, coughs, or 


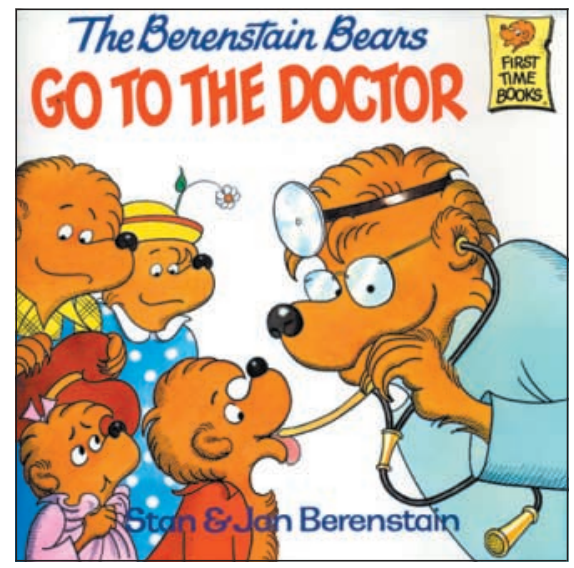

sore throats receive a prescription for "medicine"; a child with earache gets a prescription for "antibiotics and painkillers." Half of all patients leave with a prescription; this seems high for such minor complaints.

The occupational heath doctor checks the hearts of three people (a fireman, a police woman, and a builder) during Healthy Heart Day. She describes the noises she can hear ("ba-doum, ba-doum") as a "very healthy heart." We believe this assessment to be appropriate.

We are concerned about the ALS (advanced life support) skills of the hospital doctors. Two patients on monitors seem to be in ventricular tachycardia or ventricular fibrillation, but they receive no special attention. It could be a technical problem, however, considering that the patients don't look clinically compromised.

In general, examination skills are variable. Most doctors seem highly incompetent during ear, nose, and throat (see above) and abdominal examinations. Three doctors feel abdomens with the tips of their fingers (as if playing the piano).

\section{Conclusions}

In general, the image of doctors is kind, professional, and reassuring. They look young, tidy, and conservative. Many wear glasses, carry pens, or display their degrees on the walls to provide them with an aura of cleverness. They seem popular among their patients and they receive compliments, but no complaints. They are not particularly good at physical examination, but they are excellent diagnosticians. All their patients seem to get better, too. ALS skills are poor. Most doctors seem busy but never stressed. They seem focused in their work, and they look permanently happy. None of the stories suggests that doctors are under any pressure from management targets.

Some of the situations portrayed in many of these books look unrealistic. A young reader might expect to get an immediate appointment, a holistic approach, a long consultation, and a prescription. This could result in a big disappointment. Still, the presentation of the doctor as a friendly and capable person might successfully allay a child's anxiety before a visit to the doctor's.

We thank our children Paula (8 years) and Martin (3 years) for their invaluable comments during the research for this study.

Contributors: ML conceived the study, analysed the data, wrote the manuscript, and is guarantor. JAA analysed the data and edited the manuscript.

Funding: None.

Competing interests: None declared.

Ethical approval: Not required.

\section{A day in the life of a doctor \\ The team building day}

"The main purpose of a team building day is to build a team," the Facilitator begins smugly. A team building day is a cliché building day. The Facilitator can cram more clichés per square sentence and mix more metaphors than George W Bush. The Facilitator has a capital $\mathrm{F}$, and the self satisfaction of believing that the profundity of his or her insight knows no depths. The word Facilitator has the same derivation as the word facile.

"A problem shared is a problem solved." Another purpose of a team building day is embarrassment. "Let's all begin by telling our names, two things about us that no one else knows, and, if you were a dog, what breed you would be." A Rottweiler, you think, longingly.

"There is no ' $\mathrm{I}$ ' in team." Unless you are dyslexic. You resist the temptation to point out that there is a "me" in team. You also resist the even bigger temptation to point out that we would all be better off if there was no $\mathrm{F}$ in Facilitator.

"Mates is an anagram of teams. By the end of today, we will all be mates." Or meats. Or steam will be issuing from our ears.

"You use more muscles to frown than you do to smile." You wonder how many muscles you would have to use to wipe that supercilious smile off the Facilitator's face.

"A happy team makes for a happy client." The Facilitator is referring to what we used to call patients, because they needed plenty of patience. A client is a patient with attitude. A customer is a patient with health insurance.

"The team is bigger than the sum of its parts." Except the England World Cup football team, which was less than the sum of its parts. Other examples are possible.

"There is a resolution to every conflict." The team building day teaches you how to Deal with Conflict in the Workplace. Not, you regret, by improving your martial arts training. You are taught to deal with conflict by Mediation and Negotiation and Understanding and Mutual Goodwill. Sticking pins in wax images of the patronising little toe-rag in Human Relations is not Dealing with Conflict.

There are upmarket team building days and downmarket ones. An upmarket team building day involves paintball fights and smoked salmon and avocado foccacio. A downmarket team building day involves pinball machines and salmonella.

David Isaacs senior staff specialist, Department of Immunology and Infectious Diseases, Children's Hospital at Westmead, Sydney, Australia (davidi@chw.edu.au), Stephen Isaacs consultant, Waltham Forest Child and Family Consultation Service, London, Dominic Fitzgerald senior staff specialist, Department of Respiratory Medicine, Children's Hospital at Westmead 